Neuroepidemiology 2011;36:70

DOI: $10.1159 / 000322514$

\section{More Epidemiological Studies of Neurological Disorders Are Needed in the Arab Countries}

\section{Hani T.S. Benamer}

Neurology Department, New Cross Hospital, Wolverhampton, UK

I read with interest the papers by El Tallawy et al. [1, 2] regarding the epidemiology of major neurological disorders in Al Kharga district in Egypt. I commend the authors on their efforts as door-to-door neuroepidemiological studies are lacking in Egypt, the most populous Arab country, and in the Arab world [3].

However, I would like to raise several points, hoping to enrich the discussion about epidemiological studies of neurological disorders:

(1) It was surprising that the authors chose not to include an important neurological disease, multiple sclerosis, and a common neurological problem, headaches [1]. The authors did not offer any explanation in their discussion as to why they elected to do so. Could we assume that the authors found no patients with multiple sclerosis?

(2) There was no clear definition of the neurological diseases which were included in the study. The authors stated that ' $t$ ] he neurological diagnosis of the neurological disorders under study was based on the accepted criteria given by the WHO' [1]. However, they refer to two studies, by Bharucha et al. [4] and Das et al. [5], without giving a reference to any official WHO publication which defines the neurological disorders. This could be crucial when it comes to comparing the study's results with worldwide reports. For example, it is important to consider what constitutes epilepsy. Some define epilepsy as seizures that have occurred in the preceding 2,3 or 5 years. Were single-seizure episodes included in the study?

(3) The authors did not comment on whether the studied population in Al Kharga is a representative sample of the Egyptian population. This is an important issue if the results of the study are to help in planning the neurological services in Egypt.
Lastly, a rather minor point, the authors stated that ' $\mathrm{t}$ ]he UK has an ideal system to study epidemiology as health care is freely provided via the health insurance system that covers the whole population'. I agree with the first part of the statement. However, the UK health system is free at the point of delivery as it is totally funded by taxes not insurance. The whole UK population is registered in primary health clinics and therefore they are easily traceable for epidemiological studies.

I hope that this study will be followed by more epidemiological studies of neurological disorders, both from Egypt and other Arab countries. This will help in our understanding of various neurological diseases and add to the global knowledge, not to mention the useful role of these studies in planning neurological services.

\section{References}

1 El Tallawy HN, Farghaly WM, Rageh TA, Shehata GA, Metwaly NA, Elftoh NA, Hegazy AM, El Moselhy EA, Rayan I, Al Fawal BM, Abd Elhamed MA: Epidemiology of major neurological disorders project in Al Kharga District, New Valley, Egypt. Neuroepidemiology 2010;35: 291-297.

2 El Tallawy HN, Farghaly WM, Metwaly NA, Rageh TA, Shehata GA, Elfetoh NA, Hegazy AM, El-Moselhy EA, Rayan I, Al-Fawal BM, Abd Elhamed MA: Door-to-door survey of major neurological disorders in Al Kharga District, New Valley, Egypt: methodological aspects. Neuroepidemiology 2010;35:185-190.

-3 Benamer HT, Shakir RA: The neurology map of the Arab world. J Neurol Sci 2009;285:10-12.

4 Bharucha NE, Bharucha EP, Dastur HD, Schoenberg BS: Pilot survey of the prevalence of neurologic disorders in the Parsi community of Bombay. Am J Prev Med 1987;3:293-299.

5 Das SK, Sanyal K: Neuroepidemiology of major neurological disorders in rural Bengal. Neurol India 1996;44:47-58.

Hani T.S. Benamer, PhD, FRCP

Neurology Department

New Cross Hospital

Wolverhampton WV10 OQP (UK)

Tel. +44 1902695 055, Fax +44 1902695631

E-Mail benamer@doctors.org.uk

\section{KARGER}

Fax +41613061234 E-Mail karger@karger.ch www.karger.com
(C) 2011 S. Karger AG, Base

0251-5350/11/0361-0070\$38.00/0 